\title{
DEVELOPMENT AND VALIDATION OF THE SMAP ENHANCED PASSIVE SOIL MOISTURE PRODUCT
}

\author{
S. Chan', R. Bindlish', P. O'Neill', T. Jackson ${ }^{4}$, \\ J. Chaubell ${ }^{1}$, J. Piepmeier ${ }^{3}$, S. Dunbar ${ }^{1}$, A. Colliander ${ }^{1}$, F. Chen ${ }^{2}$, D. Entekhabi ${ }^{5}$, S. Yueh ${ }^{1}$, M. Cosh ${ }^{4}$, \\ T. Caldwell/U. Texas, J. Walker/Monash U., X. Wu/Monash U., \\ A. Berg/U. Guelph, T. Rowlandson/U. Guelph, A. Pacheco/AAFC, H. McNairn/AAFC, \\ M. Thibeault/CONAE, J. Martínez-Fernández/CIALE, Á. González-Zamora/CIALE, \\ E. Lopez-Baeza/U. Valencia, F. Uldall/Tech. U. Denmark, \\ M. Seyfried/USDA, D. Bosch/USDA, P. Starks/USDA, C. Holifield/USDA, J. Prueger/USDA, \\ Z. Su and R. van der Velde/U. Twente, J. Asanuma/U. Tsukuba, M. Palecki/NOAA, \\ E. Small/U. Colorado, M. Zreda/U. Arizona, J-C. Calvet/CNRM-GAME, W. Crow ${ }^{4}$ and \\ $Y$. Kerr/CESBIO-CNES
}
${ }^{1}$ NASA Jet Propulsion Laboratory, California Institute of Technology, Pasadena, CA, USA
${ }^{2}$ Science Systems and Applications, Inc., Lanham, MD, USA
${ }^{3}$ NASA Goddard Space Flight Center, Greenbelt, MD, USA
${ }^{4}$ USDA ARS Hydrology and Remote Sensing Laboratory, Beltsville, MD, USA ${ }^{5}$ Massachusetts Institute of Technology, Cambridge, MA, USA

\begin{abstract}
Since the beginning of its routine science operation in March 2015, the NASA SMAP observatory has been returning interference-mitigated brightness temperature observations at L-band $(1.41 \mathrm{GHz})$ frequency from space. The resulting data enable frequent global mapping of soil moisture with a retrieval uncertainty below $0.040 \mathrm{~m}^{3} / \mathrm{m}^{3}$ at a $36 \mathrm{~km}$ spatial scale.

This paper describes the development and validation of an enhanced version of the current standard soil moisture product. Compared with the standard product that is posted on a $36 \mathrm{~km}$ grid, the new enhanced product is posted on a 9 $\mathrm{km}$ grid. Derived from the same time-ordered brightness temperature observations that feed the current standard passive soil moisture product, the enhanced passive soil moisture product leverages on the Backus-Gilbert optimal interpolation technique that more fully utilizes the additional information from the original radiometer observations to achieve global mapping of soil moisture with enhanced clarity. The resulting enhanced soil moisture product was assessed using long-term in situ soil moisture observations from core validation sites located in diverse biomes and was found to exhibit an average retrieval uncertainty below $0.040 \mathrm{~m}^{3} / \mathrm{m}^{3}$. As of December 2016, the enhanced soil moisture product has been made available to the public from
\end{abstract}

the NASA Distributed Active Archive Center at the National Snow and Ice Data Center.

\section{INTRODUCTION}

Since the beginning of its routine science operation in March 2015, the NASA Soil Moisture Active Passive (SMAP) observatory [1] has been returning interference-mitigated brightness temperature $\left(\mathrm{T}_{\mathrm{B}}\right)$ observations at L-band frequency $(1.41 \mathrm{GHz})$ from space. The resulting data enable the production of the standard SMAP Passive Soil Moisture Product (L2_SM_P) [2] that provides frequent global mapping of soil moisture with a retrieval uncertainty below $0.040 \mathrm{~m}^{3} / \mathrm{m}^{3}$ at a $36 \mathrm{~km}$ spatial scale [3].

Given the scanning geometry of the radiometer onboard the SMAP observatory, the time-ordered $\mathrm{T}_{\mathrm{B}}$ observations in the standard Level 1 Brightness Temperature Product (L1B_TB) [4] are oversampled (i.e., exceeding the Nyquist sampling rate) in the along-scan direction. By applying the Backus-Gilbert (BG) optimal interpolation technique [5][6] to L1B_TB, additional radiometric information that was not readily available in the current standard Level 1 Gridded Brightness Temperature Product (L1C_TB) [7] can be more fully utilized for the development of higher-level geophysical products, such as the SMAP Enhanced Passive Soil Moisture Product (L2_SM_P_E). 
The development of L2_SM_P_E begins with the application of the BG optimal interpolation technique to the time-ordered $\mathrm{T}_{\mathrm{B}}$ observations in L1B_TB. This technique makes use of the antenna gain pattern information specific to the 6-meter reflector assembly onboard the observatory to achieve optimal data interpolation on a fine grid from the original data. The interpolation is considered optimal in the sense that it aims at producing interpolated values closest to what would have been measured had the instrument actually made its measurements at the interpolation points [5]. A comparison between the standard L1C_TB on a $36 \mathrm{~km}$ grid and the SMAP Level 1 Enhanced Gridded Brightness Temperature Product (L1C_TB_E) on a $9 \mathrm{~km}$ is shown in Fig. 1.

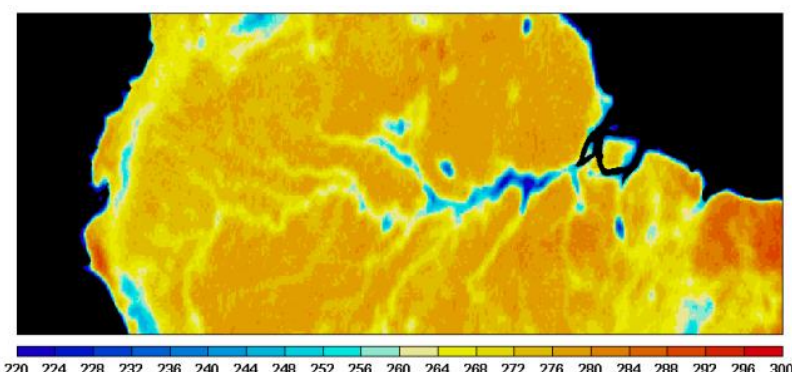

(a)

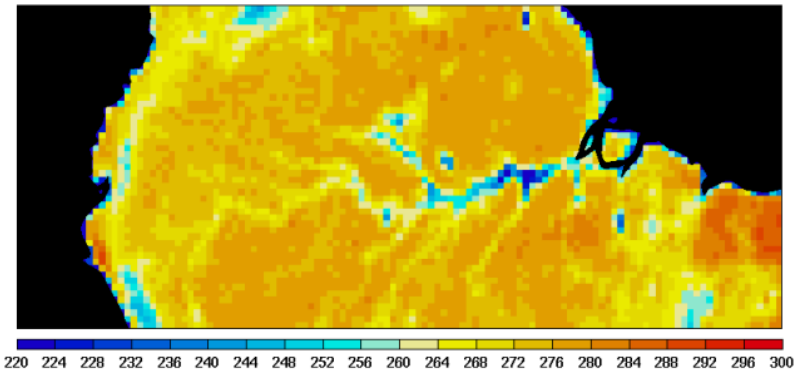

(b)

Figure 1: SMAP horizontally polarized TB observations during December 15-17, 2016 over the Amazon basin. The application of BG interpolation in L1C_TB_E (Fig. 1a) results in enhanced spatial features of the scene that are often concealed or not immediately obvious in the standard L1C_TB product (Fig. 1b).

It is clear from the comparison that the enhanced L1C_TB_E product (Fig. 1a) reveals spatial features of the scene that are concealed or not immediately obvious in the current standard L1C_TB product (Fig. 1b). Overall, the L1C_TB_E image presents a less pixelated representation of the original data, offering a higher acuity and contrast compared with the L1C_TB image. Because the information in the along-scan oversampled measurements in the original time-ordered $\mathrm{T}_{\mathrm{B}}$ data is more completely captured in L1C_TB_E, the product provides a more optimal representation of the original data for the production of L2_SM_P_E.

\section{PRODUCT DEVELOPMENT}

The development of the enhanced L2_SM_P_E follows that of the standard L2_SM_P [3]. A flowchart of the L2_SM_P_E processing is shown in Fig. 2.

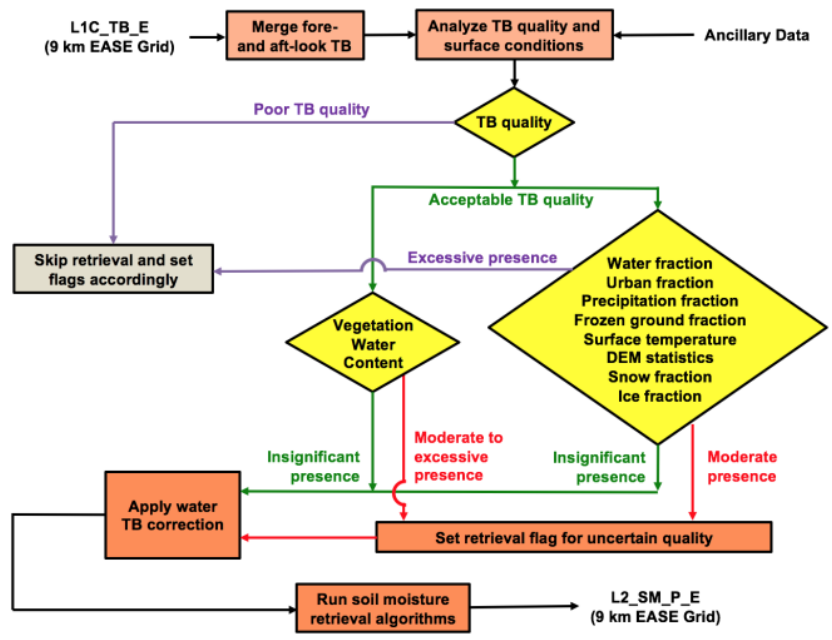

Figure 2: Processing flow of the L2_SM_P_E processor. The processor uses the L1C_TB_E product as the primary input, along with other ancillary data on finer grid resolutions, to retrieve soil moisture.

Both products share the same baseline soil moisture retrieval algorithm - the single channel algorithm that uses the vertically polarized $\mathrm{T}_{\mathrm{B}}$ channel $(\mathrm{SCA}-\mathrm{V})$ and the same set of ancillary data. The fore- and aft-look $\mathrm{T}_{\mathrm{B}}$ observations in L1C_TB_E are first combined to provide the primary input data to the L2_SM_P_E processor. External static and dynamic ancillary data preprocessed on finer grid resolutions are then brought into the processing to evaluate the feasibility and subsequent estimated quality of the retrieval. When surface conditions favorable to soil moisture retrieval are identified at a given grid cell, retrieval is performed. Corrections for water contamination, surface roughness, effective soil temperature, and vegetation water content are applied to produce the final output soil moisture retrieval field on the same $9 \mathrm{~km}$ EASE Grid 2.0 global projection [8][9] as the input L1C_TB_E. The resulting data contents of the L2_SM_P_E output files are described in the Product Specification Document [10] of the product.

Compared with the standard L2_SM_P that is posted on a $36 \mathrm{~km}$ grid, the enhanced L2_SM_P_E is posted on a $9 \mathrm{~km}$ grid. As such, the processing for L2_SM_P_E is $(36 / 9)^{2}$ or 16 times more intensive than that for L2_SM_P. Despite this increase in computation time, L2_SM_P_E processing remains relatively swift on the SMAP Science Data System (SDS). 


\section{PRODUCT VALIDATION}

The retrieval performance of L2_SM_P_E was assessed using the same set of validation methodologies described in [3]: Long-term ground truth consisting of properly scaled aggregations of in situ soil moisture observations from core validation sites serves as a primary way for product assessment. Agreement between the L2_SM_P_E soil moisture estimates and in situ data over space and time are reported in time-series correlation coefficient, bias, rootmean-square difference (RMSD), and unbiased root-meansquare difference (ubRMSD). Together, these metrics provide a more comprehensive description of product performance than any one alone. Among these metrics, the ubRMSD (in units of $\mathrm{m}^{3} / \mathrm{m}^{3}$ ) is the metric adopted by SMAP for stating product accuracy across all Level 2 through Level 4 soil moisture products. The SMAP Level 1 mission requirement for the active/passive soil moisture product accuracy is ubRMSD $=0.040 \mathrm{~m}^{3} / \mathrm{m}^{3}$ or better. The same accuracy target was also adopted for the standard L2_SM_P.

In situ soil moisture observations from a total of 15 core validation sites were used to assess the retrieval performance of L2_SM_P_E at a spatial scale similar to the effective field-of-view (EFOV) of the SMAP radiometer. Performance metrics were evaluated using 19 months (April 1, 2015 through October 31, 2016) of in situ soil moisture observations from core validation sites and the corresponding L2_SM_P_E granules from both 6:00 am descending passes and 6:00 pm ascending passes. Tables 1 and 2 provide a list of the core validation sites used in this assessment and the corresponding performance metrics, tabulated separately for the 6:00 am / 6:00 pm L2_SM_P_E data.

Table 1: Assessment of 6:00 am descending L2_SM_P_E based on a 19-month matchup with in situ soil moisture observations from 15 core validation sites. The units for ubRMSD, RMSD, and bias are $\mathrm{m}^{3} / \mathrm{m}^{3}$.

\begin{tabular}{|c|c|c|c|c|}
\hline Sites & ubRMSD & \multicolumn{1}{|c|}{ Bias } & RMSD & Corr \\
\hline Reynolds Creek & 0.040 & -0.023 & 0.046 & 0.598 \\
\hline Walnut Gulch & 0.024 & 0.011 & 0.026 & 0.813 \\
\hline TxSON & 0.032 & -0.015 & 0.036 & 0.921 \\
\hline Fort Cobb & 0.028 & -0.056 & 0.062 & 0.883 \\
\hline Little Washita & 0.022 & -0.027 & 0.035 & 0.920 \\
\hline South Fork & 0.054 & -0.062 & 0.082 & 0.646 \\
\hline Little River & 0.028 & 0.087 & 0.092 & 0.887 \\
\hline Kenaston & 0.022 & -0.040 & 0.046 & 0.854 \\
\hline Carman & 0.056 & -0.088 & 0.104 & 0.611 \\
\hline Monte Buey & 0.051 & -0.020 & 0.055 & 0.840 \\
\hline REMEDHUS & 0.042 & -0.007 & 0.042 & 0.872 \\
\hline Twente & 0.056 & 0.013 & 0.057 & 0.885 \\
\hline HOBE & 0.036 & -0.009 & 0.037 & 0.863 \\
\hline MAHASRI & 0.036 & -0.006 & 0.037 & 0.728 \\
\hline Yanco & 0.043 & 0.020 & 0.048 & 0.964 \\
\hline L2_SM_P_E & 0.038 & -0.015 & 0.054 & 0.819 \\
\hline L2_SM_P & 0.037 & -0.014 & 0.052 & 0.822 \\
\hline
\end{tabular}

A few observations can be drawn from the performance metrics listed in Tables 1 and 2. First, the enhanced
L2_SM_P_E and the standard L2_SM_P showed great similarity in all performance metrics; both demonstrated an average ubRMSD below $0.040 \mathrm{~m}^{3} / \mathrm{m}^{3}$ and thus met the SMAP Level 1 mission requirement for soil moisture retrieval accuracy. The performance of the 6:00 am data is slightly better than that of the $6: 00 \mathrm{pm}$ data. This is within expectations because the current correction in geophysical inversion for effective soil temperature described in [3] had been optimized primarily for the 6:00 am data only. Despite this limitation that led to slight degradation in retrieval accuracy the performance metrics for both 6:00 am data and 6:00 pm data are nonetheless similar.

Table 2: Assessment of 6:00 pm ascending L2_SM_P_E based on a 19-month matchup with in situ soil moisture observations from 15 core validation sites. The units for ubRMSD, RMSD, and bias are $\mathrm{m}^{3} / \mathrm{m}^{3}$.

\begin{tabular}{|c|c|c|c|c|}
\hline Sites & ubRMSD & Bias & RMSD & Corr \\
\hline Reynolds Creek & 0.042 & -0.042 & 0.059 & 0.651 \\
\hline Walnut Gulch & 0.029 & -0.019 & 0.034 & 0.676 \\
\hline TxSON & 0.028 & -0.018 & 0.034 & 0.929 \\
\hline Fort Cobb & 0.035 & -0.069 & 0.077 & 0.846 \\
\hline Little Washita & 0.026 & -0.032 & 0.041 & 0.910 \\
\hline South Fork & 0.045 & -0.087 & 0.098 & 0.764 \\
\hline Little River & 0.029 & 0.078 & 0.083 & 0.872 \\
\hline Kenaston & 0.027 & -0.051 & 0.057 & 0.828 \\
\hline Carman & 0.049 & -0.109 & 0.120 & 0.594 \\
\hline Monte Buey & 0.052 & -0.019 & 0.056 & 0.874 \\
\hline REMEDHUS & 0.045 & -0.018 & 0.048 & 0.857 \\
\hline Twente & 0.052 & 0.001 & 0.052 & 0.903 \\
\hline HOBE & 0.042 & -0.013 & 0.044 & 0.844 \\
\hline MAHASRI & 0.038 & -0.018 & 0.042 & 0.700 \\
\hline Yanco & 0.053 & 0.011 & 0.054 & 0.966 \\
\hline L2_SM_P_E & 0.039 & -0.027 & 0.060 & 0.814 \\
\hline L2_SM_P & 0.039 & -0.028 & 0.061 & 0.795 \\
\hline
\end{tabular}

Overall, the development of L2_SM_P_E results in a 9 $\mathrm{km}$ global soil moisture product that benefits from the enhanced information available in the oversampled timeordered $\mathrm{T}_{\mathrm{B}}$ observations in the original data, while retaining decent retrieval performance (ubRMSD below $0.040 \mathrm{~m}^{3} / \mathrm{m}^{3}$ ) as the standard L2_SM_P.

\section{CONCLUSION}

In this paper, the development and validation of the SMAP Enhanced Passive Soil Moisture Product were discussed. Posted on a $9 \mathrm{~km}$ grid on EASE Grid 2.0 global projection, the new product leverages on the Backus-Gilbert optimal interpolation technique that more fully utilizes the additional information from the original radiometer observations to achieve global mapping of soil moisture with enhanced clarity. Assessment of the enhanced product based on 19 months of in situ soil moisture observations from core validation sites showed that the enhanced product exhibits a level of retrieval performance (ubRMSD below 0.040 $\mathrm{m}^{3} / \mathrm{m}^{3}$ ) that met the SMAP Level 1 mission requirement for soil moisture retrieval accuracy. As of December 2016, the 
enhanced soil moisture product has been made available to the public from the NASA Distributed Active Archive Center (DAAC) at the National Snow and Ice Data Center (NSIDC).

\section{ACKNOWLEDGMENTS}

This part of the work carried out at Jet Propulsion Laboratory, California Institute of Technology was performed under a contract with National Aeronautics and Space Administration.

\section{REFERENCES}

[1] "SMAP handbook-Soil Moisture Active Passive: Mapping Soil Moisture and Freeze/thaw from Space," Jet Propulsion Laboratory, California Institute of Technology, Pasadena, CA, USA, 2014.

[2] P. E. O'Neill, S. Chan, E. G. Njoku, T. Jackson, and R. Bindlish., "SMAP L2 Radiometer Half-Orbit 36 km EASE-Grid Soil Moisture Version 4," NASA National Snow and Ice Data Center Distributed Active Archive Center, Boulder, CO, USA, 2016.

[3] S. Chan, R. Bindlish, P. O'Neill, E. Njoku, T. Jackson, A. Colliander, F. Chen, M. Mariko, S. Dunbar, J. Piepmeier, S. Yueh, D. Entekhabi, M. Cosh, T. Caldwell, J. Walker, X. Wu, A. Berg, T. Rowlandson, A. Pacheco, H. McNairn, M. Thibeault, J. MartinezFernandez, A. Gonzalez-Zamora, M. Seyfried, D. Bosch, P. Starks, D. Goodrich, J. Prueger, M. Palecki, E. Small, M. Zreda, J. Calvet, W. Crow, Y. Kerr: Assessment of the SMAP passive soil moisture product, IEEE Transactions on Geoscience and Remote Sensing, 54(8), pp. 4994-5007, Aug 2016.

[4] J. R. Piepmeier et al., "SMAP L1B Radiometer Half-orbit Time-ordered Brightness Temperatures Version 3," NASA National Snow and Ice Data Center Distributed Active Archive Center, Boulder, CO, USA, 2016.

[5] G. Poe, Optimum Interpolation of Imaging Microwave Radiometer Data, IEEE Transactions on Geoscience and Remote Sensing, 28(5), pp. 800-810. Sept. 1990.

[6] J. Chaubell, "SMAP Algorithm Theoretical Basis Document: Level 1B Enhancement Radiometer Brightness Temperature Data Product," Jet Propulsion Laboratory, California Institute of Technology, Pasadena, CA, USA, JPL D-56287, 2016.

[7] S. Chan, E. G. Njoku, and A. Colliander, "SMAP L1C Radiometer Half-orbit $36 \mathrm{~km}$ EASE-grid Brightness Temperatures Version 3," NASA National Snow and Ice Data Center Distributed Active Archive Center, Boulder, CO, USA, 2016.

[8] M. J. Brodzik, B. Billingsley, T. Haran, B. Raup, and M. H. Savoie, "EASE-Grid 2.0: Incremental but significant improvements for Earth-gridded data sets," ISPRS Int. J. Geo-Inf., vol. 1, no. 1, pp. 32-45, 2012.

[9] M. J. Brodzik, B. Billingsley, T. Haran, B. Raup, and M. H.
Savoie, "Erratum: EASE-Grid 2.0: Incremental but significant improvements for Earth-gridded data sets," ISPRS Int. J. Geo-Inf., vol. 3, no. 3, pp. 1154-1156, 2014.

[10] S. Chan and R. S. Dunbar, "SMAP Enhanced Level 2 Passive Soil Moisture Product Specification Document," Jet Propulsion Laboratory, California Institute of Technology, Pasadena, CA, USA, 2016. 